\title{
Buyang Huanwu Decoction Attenuates Infiltration of Natural Killer Cells and Protects Against Ischemic Brain Injury
}

\author{
Baokai Dou a,b,c Wenjin Zhou ${ }^{a}$ Shichun Lia Lixin Wang ${ }^{a} \quad$ Ximin Wu ${ }^{b}$ Yiming Li $^{\mathrm{b}}$ \\ Huida Guanc Changhong Wang ${ }^{c}$ Shiguo Zhu ${ }^{a}$ Zunji Ke ${ }^{a}$ Cheng Huang ${ }^{b}$ \\ Zhifei Wanga
}

aSchool of Basic Medical Sciences, Shanghai University of Traditional Chinese Medicine, Shanghai, 'School of Pharmacy, Shanghai University of Traditional Chinese Medicine, Shanghai, Institute of Chinese Materia Medica, Shanghai University of Traditional Chinese Medicine, Shanghai, China

\section{Key Words}

Buyang Huanwu Decoction - Cerebral ischemia - Natural killer cells - Nuclear factor-кB • CXCL10 - CXCR3

\begin{abstract}
Background/Aims: Natural killer (NK) cells are among the first immune cells that respond to an ischemic insult in human brains. The infiltrated NK cells damage blood-brain barrier (BBB) and exacerbate brain infarction. Buyang Huanwu Decoction (BHD), a classic Chinese traditional herbal prescription, has long been used for the treatment of ischemic stroke. The present study investigated whether BHD can prevent brain infiltration of NK cells, attenuate BBB disruption and improve ischemic outcomes. Methods: Transient focal cerebral ischemia was induced in rats by a 60-minute middle cerebral artery occlusion, and BHD was orally administrated at the onset of reperfusion, 12 hours later, then twice daily. Assessed parameters on Day 3 after ischemia were: neurological and motor functional deficits through neurological deficit score and rotarod test, respectively; brain infarction through TTC staining; BBB integrity through Evans blue extravasation; matrix metalloproteinase-2/9 activities through gelatin

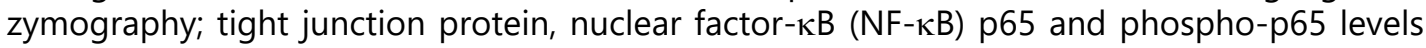
through Western blotting; NK cell brain infiltration and CXCR3 levels on NK cells through flow cytometry; interferon- $\gamma$ production through ELISA; CXCL10 mRNA levels through realtime PCR; CXCL10 expression and p65 nuclear translocation through immunofluorescence staining. Results: BHD markedly reduced brain infarction, improved rotarod performance, and attenuated BBB breakdown. Concurrently, BHD attenuated the upregulation of matrix metalloproteinase-2/9 activities and the degradation of tight junction proteins in the ischemic brain. Infiltration of NK cells was observed in the ischemic hemisphere, and this infiltration was blunted by treatment with BHD. BHD suppressed brain ischemia-induced interferon- $\gamma$
\end{abstract}

\begin{tabular}{ll}
\hline Zhifei Wang & School of Basic Medical Sciences, Shanghai University of Traditional Chinese Medicine \\
& 1200 Cailun Road, Pudong New District, Shanghai (China) \\
& Tel. 86-21-51323172, E-Mail zfwang@shutcm.edu.cn
\end{tabular}


and chemokine $\mathrm{CXCL} 10$ production. Furthermore, BHD significantly reduced the expression of CXCR3 on brain-infiltrated NK cells. Strikingly, BHD did not affect NK cell levels or its CXCR3 expression in the spleen or peripheral blood after brain ischemia. The nuclear translocation of NF-KB p65 and phospho-p65 in the ischemic brain was inhibited by BHD. Conclusion: Our findings suggest that BHD prevents brain infiltration of NK cells, preserves BBB integrity and eventually improves ischemic outcomes. The inhibitory effects of BHD on NK cell brain invasion may involve its ability of suppressing NF- $\kappa B$-associated CXCL10-CXCR3-mediated chemotaxis. Notably, BHD only suppresses NK cells and their CXCR3 expression in the ischemic brain, but not those in periphery.

(C) 2018 The Author(s)

Published by S. Karger AG, Basel

\section{Introduction}

Immune responses are closely involved in all stages of ischemic cascade, and participate in the determination of overall outcome after a stroke [1,2]. Natural killer (NK) cells are key components of the innate immunity, and are among the first immune cells that respond to pathogen invasion through cytolytic activity without prior sensitization. NK cells also modulate the adaptive immunity via cytokine production, and possess antigen-specific immunologic memory [3]. Due to its unique immunology features that orchestrate innate and adaptive immune responses, NK cells receive increasing attentions in the study of brain ischemia [4].

NK cells infiltrate into the brain under numerous neurological conditions, including stroke [5]. Abundant NK cells are found in infarct and peri-infarct brain regions in postmortem studies, and infiltration of NK cells peaks at 2 to 5 days after ischemic stroke [6, 7]. Significant infiltration of NK cells is also found in rodents subjected to focal cerebral ischemia [6-8]. The recruitment of NK cells is initiated by chemokines, which are immediately produced by ischemic brain cells [6-8]. The infiltrated NK cells lose tolerance to neurons, augment local inflammation, increase blood-brain barrier (BBB) permeability, and eventually exacerbate brain infarction $[6,7]$. The mechanisms underlying NK cell-mediated ischemic neuronal death may involve cytotoxic effects, exacerbated neuronal excitability, and upregulated NK cell stimulatory receptor and ligand for NK cell inhibitory receptor on neurons [6]. Depletion of NK cells can diminish brain infarction, suggesting the important role of NK cells in the ischemic brain injury [7]. Therefore, therapeutic strategies that inhibit post-stroke NK cell brain invasion may improve stroke outcomes.

Buyang Huanwu Decoction (BHD), originally recorded in "Yi Lin Gai Cuo" (Correction on Errors in Medical Classics), is a classic Chinese traditional herbal prescription and has been commonly used for the treatment of ischemic stroke for more than two centuries in China. From a traditional Chinese medical perspective, Qi deficiency and blood stasis are the main pathogenic features of ischemic stroke. Qi is the foundation of traditional Chinese medicine. It is loosely translated as vital energy and is considered to be the force that enlivens human body. BHD can tonify Qi flow, promote blood circulation and eventually revitalize stroke patients. Meta-analyses have demonstrated the efficacy and safety of BHD for acute ischemic stroke in both clinical applications and experimental settings [9, 10]. Transcriptome and proteome analyses reveal that BHD can regulate genes and proteins that inhibit inflammation and ameliorate BBB disruption 24 hours after focal cerebral ischemia in mice [11-13]. As aforementioned, brain ischemia-induced inflammation recruits immune cells, including NK cells, which breach BBB integrity, release massive proinflammatory cytokines, amplify inflammatory responses, and accelerate brain infarction. Hence, the present study investigated whether BHD would prevent infiltration of NK cells, attenuate BBB disruption, and ameliorate ischemic outcomes in a rat model of transient focal cerebral ischemia. 


\section{Cellular Physiology Cell Physiol Biochem 2018;50:1286-1300 \begin{tabular}{l|l|l} 
and Biochemistry Published online: 25 October 2018 & $\begin{array}{l}\text { (c) } 2018 \text { The Author(s). Published by S. Karger AG, Basel } \\
\text { www.karger.com/cpb }\end{array}$ \\
\hline
\end{tabular} \\ Dou et al.: BHD Inhibits NK Cell Infiltration into Ischemic Brain}

\section{Materials and Methods}

\section{BHD preparation and quality control}

BHD is composed of Huangqi (Astragali Radix), Danggui (Angelicae sinensis Radix), Chishao (Paeoniae Radix Rubra), Chuanxiong (Chuangxiong Rhizoma), Taoren (Persicae Semen), Honghua (Carthami Flos), and Dilong (Pheretima) at a ratio of 120:6:4.5:3:3:3:3 (dry weight). All herbs were purchased from Kangqiao Chinese Medicine Tablet Co., LTD (Shanghai, China). The mixture was boiled in distilled water at $100{ }^{\circ} \mathrm{C}$ for 60 minutes twice. The combined filtrate was concentrated to $2 \mathrm{~g} / \mathrm{mL}$ (equivalent to dry weight of raw materials).

As quality control, high Performance Liquid Chromatography (HPLC) analysis of BHD was performed on an Agilent 1260 liquid chromatograph system (Agilent Technologies Inc., USA). Detection of the analytes was conducted using the DAD detector and Discovery C18 HPLC column $(250 \times 4.6 \mathrm{~mm}, 5 \mu \mathrm{m})$. The column was operated at $35^{\circ} \mathrm{C}$, and the injection volume was $20 \mu \mathrm{L}$. The mobile phase was consisted of 100 $\%$ acetonitrile (A) and the water contained $0.05 \%$ phosphoric acid (B) at a flow rate of $1.0 \mathrm{~mL} / \mathrm{minute}$. The gradient profile was 0-40 minutes, 10-60\% acetonitrile. From 0 to 6 minutes, $270 \mathrm{~nm}$ was for the detection of gallic acid; from 6 to 8.3 minutes, $290 \mathrm{~nm}$ was for ligustrazine; from 8.3 to 10 minutes, $403 \mathrm{~nm}$ was for hydroxyl safflower yellow A; from 10 to 13.5 minutes, $230 \mathrm{~nm}$ was for paeoniflorin; from 13.5 to 15 minutes, $260 \mathrm{~nm}$ was for calycosin-7-glucoside; from 15 to 17 minutes, $290 \mathrm{~nm}$ was for ferulic acid; from 17 to 40 minutes, $255 \mathrm{~nm}$ was for formononetin. For quantitation, a mixed stock solution was prepared by dissolving gallic acid, ligustrazine, hydroxyl safflower yellow A, paeoniflorin, calycosin-7-glucoside, ferulic acid and formononetin $(1 \mathrm{mg} / \mathrm{mL})$ in methanol and then further diluted to achieve $100 \mu \mathrm{g} / \mathrm{mL}$ for each bioactive ingredient. BHD (2 mL) solution was diluted to $10 \mathrm{~mL}$ with methanol and filtered through a $0.45 \mu \mathrm{m}$ membrane filter. The contents of seven ingredients were calculated via one point external standard method, and the assays were repeated twice.

The analysis of astragaloside IV in BHD by UHPLC-ESI/MS was performed on an Agilent 1290 UHPLC system with 6410 triple quadrupole mass spectrometer (Agilent Technologies, Santa Clara, CA, USA) with an electrospray ionization (ESI) source. The analytes were separated on a HSS T3 column $(2.1 \times 100 \mathrm{~mm}, 1.8$ $\mu \mathrm{m}$, Waters, Milford, USA) at $45^{\circ} \mathrm{C}$. The mobile phase was composed of $0.1 \%$ formic acid in water (Solvent A) and acetonitrile (Solvent B) using an isocratic elution of $65 \% / 35 \%(v / v)$ at 0-10 minutes. The flowrate was $0.3 \mathrm{ml} /$ minute and the injection volume was $2 \mu \mathrm{L}$. The 6410 mass spectrometer was operated in negative electrospray ionization mode and the MS parameters were set as following: capillary $3500 \mathrm{~V}$, gas temperature $350^{\circ} \mathrm{C}$, gas flow $10 \mathrm{~L} /$ minute, and nebulizer pressure 40 psi. Quantification was obtained using multiple reaction monitoring (MRM) mode at $\mathrm{m} / \mathrm{z}$ transitions of $829.5 \rightarrow 783.4$ for astragaloside IV, and dependent parameters used for analysis were $140 \mathrm{~V}$ (Fragmentor) and $20 \mathrm{~V}$ (Collision energy). A stock solution of astragaloside IV $(1 \mathrm{mg} / \mathrm{mL})$ was prepared by dissolving in methanol and then further diluted with purified water to achieve quality control samples at concentrations of 500, 2000, $5000 \mathrm{ng} / \mathrm{mL}$. BHD $(0.1 \mathrm{~mL})$ solution was diluted to $10 \mathrm{~mL}$ with purified water. The mixtures were then vortex-mixed for 1 minute and centrifuged at $15,000 \times g$ for 10 minutes. An aliquot $2 \mu \mathrm{L}$ of the supernatant was injected into the LC-MS/MS system. The content of astragaloside IV in BHD was quantitatively determined by calibration curve of $\mathrm{Y}=0.6871 \mathrm{X}-175.3625$, which was linear in the concentration ranging from 500 to $5000 \mathrm{ng} / \mathrm{mL}$ for astragaloside IV with a correlation coefficients $\left(R^{2}\right)$ of 0.9941 . All data were processed using Agilent MassHunter Qualitative Analysis B.04.00 Software (Agilent Technologies Inc., USA).

\section{Animal surgery and drug administration}

All animal experiments were performed according to protocols approved by the Experimental Animal Ethical Committee, Shanghai University of Traditional Chinese Medicine. One hundred and forty-six male Sprague-Dawley rats (200-220 g, Vital River Laboratory Animal Technology Co., Ltd., Beijing, China) underwent one-hour right middle cerebral artery occlusion (MCAO) under inhalational anesthesia $(2.5 \%$ isoflurane) as previously described [14-17]. A laser Doppler flowmetry (Powerlab ML191, ADInstruments, Australia) was used to monitor the regional cerebral blood flow $(1.5 \mathrm{~mm}$ posterior, $5 \mathrm{~mm}$ lateral to the bregma). Rats whose blood flow reduced to $27 \pm 0.5 \%$ of the baseline were included. MCAO rats were randomized to BHD or vehicle treatment. BHD was orally administrated at the onset of reperfusion, 12 hours later, and then twice daily for three days.

\section{KARGER}




\section{Cellular Physiology Cell Physiol Biochem 2018;50:1286-1300 \begin{tabular}{ll|l} 
and Biochemistry & Dublished online: 25 October 2018 & $\begin{array}{l}\text { (c) } 2018 \text { The Author(s). Published by S. Karger AG, Basel } \\
\text { www.karger.com/cpb }\end{array}$
\end{tabular}}

Dou et al.: BHD Inhibits NK Cell Infiltration into Ischemic Brain

Behavioral tests

To assess the effects of BHD on the functional recovery of MCAO rats, the accelerating rotarod test and neurological deficit score were performed by an investigator who was blind to the treatment condition, as previously described [14-17]. For the accelerating rotarod test, rats were placed on an accelerating rotarod apparatus (Panlab, Barcelona, Spain) in which the speed was accelerated from 4 to 40 rpm over four minutes. Three consecutive days before MCAO, rats received once-daily training sessions of three trials separated by 30-minute intervals. The longest amount of time each rat remained on the rod was recorded as baseline. Rats underwent three trials per day on the rotarod for three consecutive days after MCAO, and the best performance of each rat was recorded for that day.

For the neurological deficit score, rats were assessed for motor, sensory, and reflex performance using a modified 12-point neurological scoring system. Seven tests of motor performance (flexion of forelimb, flexion of hind limb, head movement $10^{\circ}$ to the vertical axis, inability to walk straight, circling towards the paralytic side, falling to the paralytic side, and immobility), two tests of sensation (visual and tactile placement and a proprioceptive test), and three reflex tests (pinna, corneal, and startle reflex) were evaluated. A score of 0 (normal) or 1 (abnormal) was given for each test.

\section{Brain infarction measurement}

TTC staining was performed to determine the brain infarct volume. On Day 3 after MCAO, six 2-mm coronal brain sections were stained with $2 \%$ TTC (2, 3,5-triphenyl tetrazolium chloride, Sigma, USA) at 37 ${ }^{\circ} \mathrm{C}$ for 15 minutes. The infarct area in white was measured using Image (free download at http://rsbweb. nih.gov/ij/). The infarct volume was calculated as the sum of infarct area times the average slice thickness (2 $\mathrm{mm})$.

\section{Evans blue extravasation}

BBB integrity was evaluated by Evans blue extravasation on Day 3 after MCAO, as previously described [15]. Evans blue ( $2 \%$ in saline, $4 \mathrm{~mL} / \mathrm{kg}$, i.v., Sigma) was given at the onset of reperfusion. To remove the intravascular dye, rats were transcardially perfused with PBS. Each brain hemisphere was weighted, homogenized in $2 \mathrm{~mL} 50 \%$ trichloroacetic acid, and then centrifuged (4000×g for 40 minutes). The supernatant was measured for absorbance at $620 \mathrm{~nm}$ by spectrophotometry. The results were calculated against a standard curve and expressed as $\mu \mathrm{g} / \mathrm{g}$ tissue.

\section{Gelatin zymography}

Gelatin zymography was performed to measure the activities of matrix metalloproteinase (MMP)2 and MMP-9 on Day 3 after MCAO, as previously described [15]. Tissues from ipsilateral cortex were homogenized in a lysis buffer (50 mmol/L Tris-HCl, pH 7.4, $150 \mathrm{mmol} / \mathrm{L} \mathrm{NaCl,} 1 \%$ Triton X-100), and centrifuged. Aliquots containing equal amounts of protein from each sample were incubated for 1 hour at $4{ }^{\circ} \mathrm{C}$ with gelatin-Sepharose 4B (GE Healthcare, Little Chalfont, UK) with constant shaking. The pellets were washed with a working buffer (lysis buffer without Triton X-100) and resuspended in $100 \mu \mathrm{L}$ of elution buffer (working buffer with $10 \%$ dimethylsulfoxide) for 30 minutes and then centrifuged. The samples were loaded on $10 \%$ zymogram gelatin gels containing $1 \%$ gelatin. After electrophoresis, the gels were incubated in renaturing buffer $\left(50 \mathrm{mmol} / \mathrm{L}\right.$ Tris- $\mathrm{HCl}, \mathrm{pH} 7.6,5 \mathrm{mmol} / \mathrm{L} \mathrm{CaCl}_{2}, 1 \mu \mathrm{mol} / \mathrm{L} \mathrm{ZnCl}_{2}, 2.5 \%$ Triton $\mathrm{X}-100$ ) for 45 minutes twice at room temperature, washed with washing buffer (renaturing buffer without Triton X-100) for 30 minutes twice, and then incubated in developing buffer ( $50 \mathrm{mmol} / \mathrm{L}$ Tris- $\mathrm{HCl}, \mathrm{pH} 7.6,5$ $\mathrm{mmol} / \mathrm{L} \mathrm{CaCl}_{2}, 1 \mu \mathrm{mol} / \mathrm{L} \mathrm{ZnCl}_{2}, 0.02 \% \mathrm{Brij}-35$,) for two days at $37^{\circ} \mathrm{C}$. The gels were stained for 1 hour in 0.5 $\%$ Coomassie blue (Yeasen, Shanghai, China) and then washed with water to obtain the clearest background for photography.

\section{Flow cytometry}

NK cell levels and CXCR3 expression on the surface of NK cells in the ischemic brain, spleen and peripheral blood were examined by flow cytometry. On Day 3 after MCAO, 3 to $5 \mathrm{~mL}$ blood was withdrawn via cardiac puncture, and then the rats were transcardially perfused with PBS. Brain and spleen were quickly removed. Brain tissues from ipsilateral hemisphere were enzymatic digested in HBSS containing $1 \mathrm{mg} / \mathrm{mL}$ Collagenase II and $10 \mu \mathrm{g} / \mathrm{mL}$ DNase I at $37^{\circ} \mathrm{C}$ for 60 minutes, pressed through a $40 \mu \mathrm{m}$ filter using a piston, and centrifuged at $400 \times \mathrm{g}$ for 10 minutes at $4{ }^{\circ} \mathrm{C}$. Cells were separated from myelin and debris using a 3-step 


\section{Cellular Physiology Cell Physiol Biochem 2018;50:1286-1300 \begin{tabular}{l|l|l} 
DOI: 10.1159/000494587 & $\begin{array}{l}\text { O } 2018 \text { The Author(s). Published by S. Karger AG, Basel } \\
\text { www.karger.com/cpb }\end{array}$
\end{tabular} \\ Dou et al.: BHD Inhibits NK Cell Infiltration into Ischemic Brain}

Percoll density gradient ( $4 \mathrm{~mL} 30 \%, 3.5 \mathrm{~mL} 37 \%$ and $3.5 \mathrm{~mL} 70 \%$ Percoll solution) and then centrifuged with low acceleration at $1000 \times \mathrm{g}$ for 10 minutes at $4{ }^{\circ} \mathrm{C}$. Lymphocytes in the interphase layer between the $70 \%$ and $37 \%$ Percoll were harvested carefully, washed and re-suspended in $3 \%$ FBS/HBSS. Lymphocytes in the blood and spleen were separated using Lymphocyte Separation Medium (Dakewe, Shenzhen, China) according to the manufacturer's protocol. Cells were counted and then incubated for 30 minutes at $4{ }^{\circ} \mathrm{C}$ with PE-conjugated anti-rat CD161 (BioLegend, USA)/APC-conjugated anti-rat CD3 (BioLegend), or APCconjugated anti-rat CD161 (BioLegend)/FITC-conjugated anti-rat CD3 (BioLegend)/PE-conjugated antirat CXCR3 (R\&D Systems, USA), and their corresponding isotype controls. After two washes, cells were fixed with $2 \%$ paraformaldehyde at $4{ }^{\circ} \mathrm{C}$. FACS was performed on BD AccuriTM C6 flow cytometer (BD Biosciences, USA). Data were analyzed using FlowJo (version 10, USA).

\section{Western blotting}

The protein levels of Occludin, ZO-1, NF-kB p65, Histone H3 and $\beta$-actin in the ipsilateral cortex on Day 3 after MCAO were detected by Western blotting. Briefly, brain tissues were dissected and sonicated in RIPA lysis buffer (Yeasen) containing protease inhibitor cocktails (Yeasen). The lysates were centrifuged at 12, $000 \mathrm{rpm}$ for 10 minutes at $4{ }^{\circ} \mathrm{C}$. For p65 and phospho-p65 detection, cytoplasmic and nuclear extracts were prepared using a Nuclear and Cytoplasmic Protein Extraction Kit (Beyotime, Shanghai, China) according to the manufacturer's protocol. Protein concentrations were measured using the BCA method (Thermo Fisher Scientific). Samples with equal total protein were separated on $10 \%$ SDS-polyacrylamide gels and transferred onto a nitrocellulose membrane (Millipore). The blots were blocked and incubated overnight at $4{ }^{\circ} \mathrm{C}$ with rabbit anti-Occludin $(1: 125$, Thermo Fisher Scientific), rabbit anti-ZO-1 (1:500, Thermo Fisher Scientific), mouse anti-p65 (1:1000, Cell Signaling Technology), rabbit anti-phospho-p65 (1:1000, Cell Signaling Technology), rabbit anti-Histone H3 (1:1000, Abcam), or mouse anti- $\beta$-actin (1:5000, Sigma). After washing, the membranes were incubated with appropriate HRP-conjugated secondary antibodies (1:5000, Kangchen, Shanghai, China) for two hours at room temperature. Chemiluminescence was developed by Immobilon $^{\mathrm{TM}}$ Western Chemiluminescent HRP Substrate (Millipore) and detected by ChemiDoc ${ }^{\mathrm{TM}}$ Touch Imaging System (Bio-Rad).

\section{ELISA}

On Day 3 after MCAO, the ipsilateral cortex was homogenized in PBS, and the total protein concentration was adjusted to equal amount. IFN $-\gamma$ protein levels in homogenates were detected by a rat IFN- $\gamma$ ELISA kit (Dakewe, Shenzhen, China), according to the manufacturer's instructions.

\section{Immunohistochemistry and immunofluorescence staining}

The infiltration of NK cells in the ischemic cortex was assessed by immunohistochemistry on Day 3 after MCAO. Brains were fixed following transcardial perfusion, dehydrated, and cryo-cut. Free-floating sections $(30 \mu \mathrm{m})$ were incubated with mouse anti-CD161 (1:200, BD Pharmingen), followed biotinylated anti-mouse IgG (Yeasen) and then strept avidin-biotin peroxidase complex (Yeason). The staining was visualized with diaminobenzidine kit (Yeasen) and captured by Zeiss AXIO Imager M2 microscope.

The expression of CXCL10 and its colocalization with neurons, endothelial cells, astrocytes, microglia and neutrophils were examined by immunofluorescence staining. The p65 was immunofluorescence stained with DAPI counterstaining. Free-floating sections $(30 \mu \mathrm{m})$ were incubated with mouse anti-p65 (1:500, Cell Signaling Technology), and goat anti-CXCL10 (1:50, Santa Cruz Biotechnology) in combination with rabbit anti-NeuN (1:1000, Abcam), mouse anti-RECA-1 (1:500, Abcam), rabbit anti-GFAP (1:400, Abcam), rabbit anti-Iba1 (1:1000, Wako, Japan), or rabbit anti-MPO (1:50, Abcam) followed by appropriate Alexa Fluor 488 and 594-conjugated secondary antibodies (1:400, Jackson ImmunoResearch). Immunolabeling signals were captured by a Leica SP8 Confocal Microscope (double staining CXCL10 with NeuN, RECA-1, GFAP, and Iba1) and a Zeiss LSM880 Confocal Microscope (double staining CXCL10 with MPO, and p65 nuclear translocation). ImageJ was used to quantify the staining results. 


\section{Cellular Physiology Cell Physiol Biochem 2018;50:1286-1300

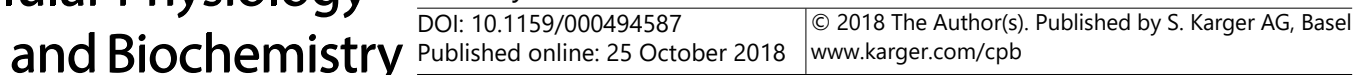

RNA extraction and real-time PCR

Total RNA from ipsilateral cortex on Day 3 after MCAO was isolated using TRIzol reagent (Thermo Fisher Scientific) and reverse-transcribed into cDNA using RevertAid First Strand cDNA Synthesis Kit (Thermo Fisher Scientific). Real-time PCR was performed using StepOnePlus Real-Time PCR System (Thermo Fisher Scientific) with SYBR ${ }^{\circledR}$ Select Master Mix (Thermo Fisher Scientific) according to the manufacturer’s instructions. The mRNA levels were normalized against $\beta$-actin and presented as $2^{-\Delta \Delta C T}$.

\section{Statistical analysis}

Data are expressed as mean \pm SEM. Statistical analysis was performed using GraphPad Prism 5. For behavioral data, two-way repeated-measures analysis of variance was performed. Comparisons between two groups and multiple groups were evaluated by Student's $t$-test and one-way analysis of variance followed by Tukey's post-hoc comparisons, respectively. Differences were considered statistically significant at $P<0.05$.

\section{Results}

\section{Quality control of BHD}

According to the Chinese Pharmacopoeia and previous reports [18, 19], seven representative bioactive ingredients were identified in BHD using HPLC analysis (Fig. 1A and B). These ingredients included gallic acid, ligustrazine, hydroxyl safflower yellow A, paeoniflorin, calycosin-7-glucoside, ferulic acid, and formononetin, and their contents were $0.114,0.034,0.076,0.544,0.3,0.181$, and $0.039 \mathrm{mg} / \mathrm{g}$ dry weight of raw materials, respectively. Astragaloside IV, a representative bioactive ingredient of Huangqi, was identified using UHPLC-ESI/MS (Fig. 1C and D), and its content in BHD was $78.5 \mu \mathrm{g} / \mathrm{g}$ dry weight of raw materials.

\section{BHD improved functional recovery and ameliorated brain infarction in MCAO rats}

Brain ischemia induced severe neurological and motor functional deficits as indicated by the neurological deficit score and accelerating rotarod test in MCAO rats. MCAO dramatically increased the neurological deficit score and reduced the length of time that rats were able to stay on an accelerating rotarod, and these deficits persisted for at least three days. BHD at $14 \mathrm{~g} / \mathrm{kg}$ /day robustly ameliorated neurological deficit score from $5.0 \pm 0.5$ to $2.0 \pm 0.5$ on Day 3 after MCAO $(P<0.01$, Fig. 2A). BHD also markedly increased the rotarod retention time from $63.4 \pm 11.9$ to $118.4 \pm 13.4$ seconds on Day 2, and from $53.4 \pm 8.7$ to $105.2 \pm 13.7$ seconds on Day 3 after MCAO $(P<0.05$, Fig. $2 \mathrm{~B})$. At this dosage, BHD significantly reduced the brain infarct volume from $290.6 \pm 25.2$ to $168.6 \pm 23.8 \mathrm{~mm}^{3}$ on Day $3(P<0.05$, Fig. $2 \mathrm{C}$ and D). BHD at lower dosage of $7 \mathrm{~g} / \mathrm{kg} /$ day only had a tendency to reduce neurological deficit score and

Fig. 1. Quality control of BHD preparation by HPLC fingerprint and UHPLC-ESI/MS analysis. (A and B) Seven representative bioactive ingredients were identified in BHD using HPLC analysis: 1. gallic acid, 2. ligustrazine, 3. hydroxyl safflower yellow A,

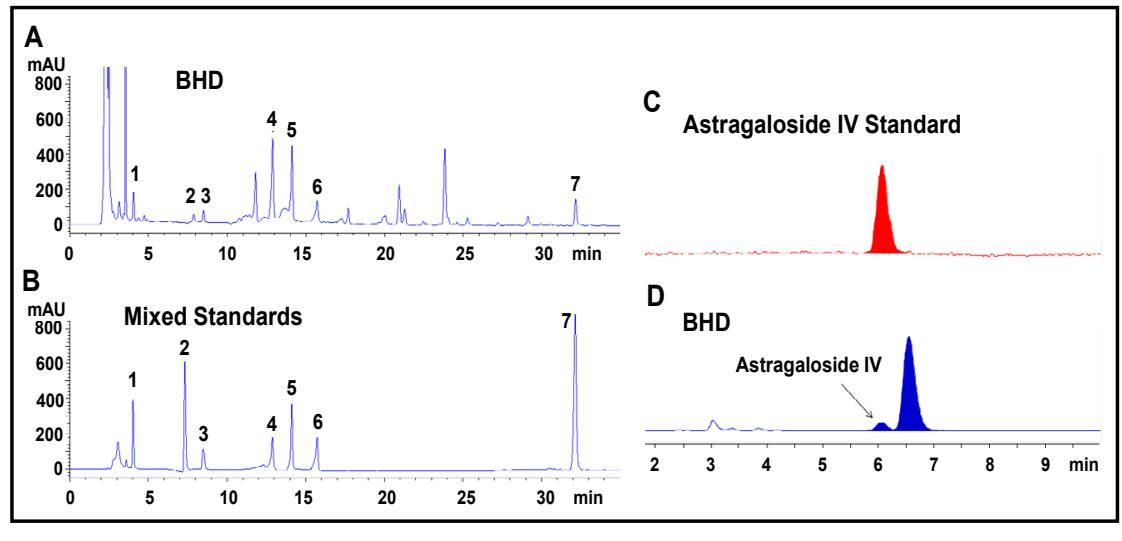
4. paeoniflorin, 5 . calycosin-7-glucoside, 6. ferulic acid, and 7. formononetin. (C and D) Astragaloside IV in BHD was detected by UHPLC-ESI/MS. 
brain infarction, and had no effect on rotarod performance. Compared with $7 \mathrm{~g} / \mathrm{kg} / \mathrm{day}$, BHD at $14 \mathrm{~g} / \mathrm{kg} /$ day produced significant better protective effects in neurological deficit, motor functional deficit and brain infarction. Therefore, $14 \mathrm{~g} / \mathrm{kg} /$ day BHD was used in the subsequent experiments.

Fig. 2. BHD improved functional recovery and reduced brain infarct volume in MCAO rats. (A) The increased neurological deficit score in MCAO rats was markedly attenuated by $14 \mathrm{~g} / \mathrm{kg} /$ day BHD treatment on Day 3 after ischemia. (B) MCAO rats receiving 14 $\mathrm{g} / \mathrm{kg} /$ day BHD treatment spent much longer time on an accelerating rotarod compared with untreated MCAO group on Days 2 and

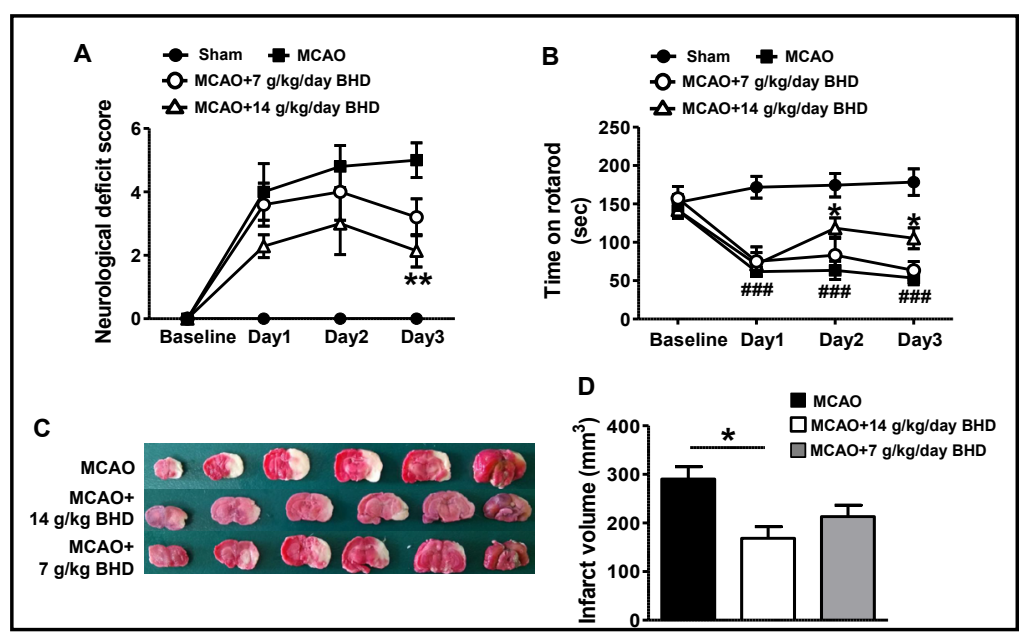
3. (C) BHD at $14 \mathrm{~g} / \mathrm{kg} /$ day significantly reduced brain infarct volume on Day 3. \#\#\# $\mathrm{P}<0.001$ compared with sham control; ${ }^{*} \mathrm{P}<0.05$, ${ }^{* *} \mathrm{P}<0.01$ compared with MCAO group; $\mathrm{n}=8$.

Fig. 3. BHD attenuated brain ischemia-induced BBB disruption, upregulation of MMP2 and 9 activities, and tight junction proteins degradation on Day 3 after MCAO. (A) BHD robustly attenuated transient MCAO-induced Evans blue extravasation in the ipsilateral hemisphere. (B) BHD suppressed the increased MMP-2 and 9 activities in ischemic cortex as assessed by gelatin zymography. MCAO robustly reduced protein levels of tight junction ZO-1 (C and D) and Occludin ( $\mathrm{E}$ and $\mathrm{F}$ ) in the ischemic cortex, and these reductions were

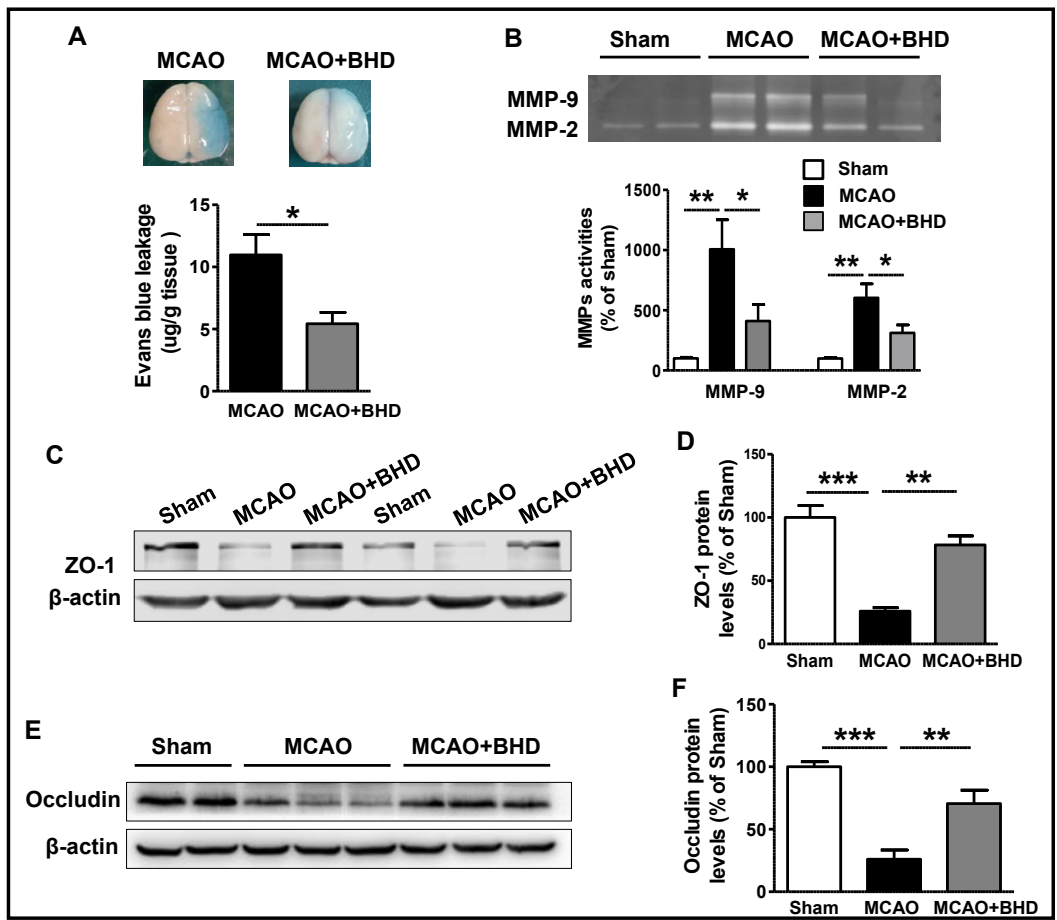
prevented by BHD treatment. ${ }^{*}<0.05,{ }^{* *} \mathrm{P}<0.01,{ }^{* * *} \mathrm{P}<0.001 ; \mathrm{n}=6$. 
BHD attenuated BBB disruption, reduced MMP-2 and 9 activities, and preserved tight junction protein levels

Severe Evans blue extravasation was observed in the ipsilateral hemisphere compared with the contralateral side in MCAO rats. BHD robustly attenuated the leakage from $11.0 \pm 1.6$ to $5.4 \pm 0.9 \mu \mathrm{g} / \mathrm{g}$ in the ischemic brain on Day $3(P<0.05$, Fig. 3A). MMPs are known to mediate post-ischemic BBB disruption by degrading the extracellular matrix, tight junction proteins, and basal lamina proteins [20]. Among all MMPs, MMP-2 and 9 have been intensively studied for their roles in BBB disruption after brain ischemia. As shown in the zymography gel, there was a 10-fold increase for total MMP-9 activities and a 6-fold increase for total MMP-2 activities in the cortex of MCAO rats compared with those in sham-operated rats (Fig. 3B). BHD markedly decreased MMP-9 and 2 activities to 4-fold and 3-fold of those in sham controls, respectively. As a result, protein levels of tight junction ZO-1 and Occludin in the ischemic cortex decreased to one fourth of those in sham-operated rats, whereas BHD robustly increased the protein levels of ZO-1 and Occludin to more than $70 \%$ of those in sham controls (Fig. 3C-F). Therefore, BHD may attenuate post-ischemic BBB disruption through inhibiting MMP-2 and 9 activities and consequently preventing the reduction of ZO-1 and Occludin protein levels in the ischemic brain.

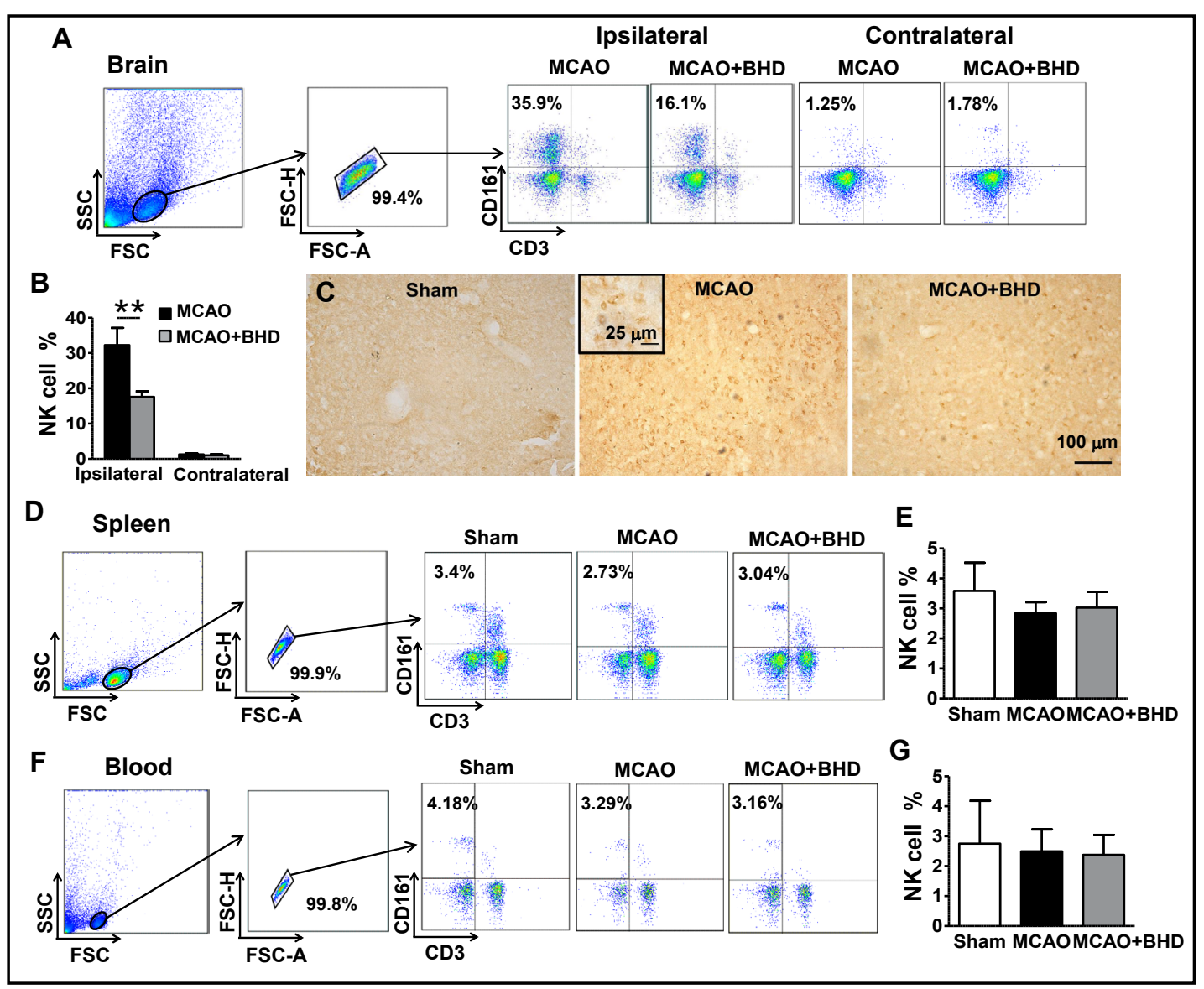

Fig. 4. BHD inhibited the infiltration of NK cells into the ischemic brain, but did not affect NK cell percentage in the periphery on Day 3 after MCAO. Infiltration of NK cells to the ischemic cortex was detected by flow cytometry (A and B). Infiltration of $\mathrm{CD} 161^{+}$cells were observed in the ischemic cortex as assessed by immunohistochemistry (C). BHD markedly inhibited the brain infiltration of CD161 ${ }^{+}$cells. There was a slight but not significant decrease in NK cell percentage of leukocytes in the spleen (D and E) and blood (F and G), and BHD had no effect on NK cell percentage in the periphery. ${ }^{* *} \mathrm{P}<0.01 ; \mathrm{n}=8$. 


\section{\begin{tabular}{ll} 
Cellular Physiology & Cell Physiol Biochem 2018;50:1286-1300 \\
\hline DOl: 10.1159/000494587 & |O 2018 The Author(s). Published by S. Karger AG, Basel
\end{tabular}

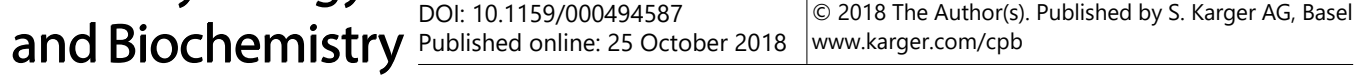 \\ Dou et al.: BHD Inhibits NK Cell Infiltration into Ischemic Brain}

BHD inhibited the infiltration of NK cells into the ischemic brain, but did not affect NK cell levels in the spleen and blood

Rat NK cells can be identified by fluorescence staining of CD161+CD3 lymphocytes using flow cytometry [8]. In the brain, nearly one third $(32.2 \pm 4.9 \%)$ of the infiltrating lymphocytes were NK cells in the ipsilateral hemisphere of MCAO rats, compared with $1.3 \pm 0.2 \%$ in the contralateral hemisphere on Day 3 after MCAO (Fig. 4A and B). BHD robustly decreased the percentage of NK cells to $17.6 \pm 1.5 \%$ in the ischemic hemisphere $(P<0.01)$, but did not affect that in the non-ischemic hemisphere $(1.0 \pm 0.3 \%)$. The results from flow cytometry were confirmed by immunohistochemistry. As shown in Fig. 4C, there were abundant CD161 ${ }^{+}$cells accumulating in the ischemic cortex. CD161 is primarily expressed on NK cells, and also on NKT cells, a subset of T cells and dendritic cells. BHD markedly reduced the infiltration of CD161+ cells. Meanwhile, in the spleen and blood, there was a slight and not significant decrease in the percentage of NK cells in lymphocytes in MCAO rats compared with those in sham-operated rats. NK cell levels remained unaffected following BHD treatment in both spleen (Fig. 4D and E) and blood (Fig. 4F and G) compared with those in MCAO rats.

\section{BHD reduced interferon- $\gamma$ production and downregulated CXCL10 levels in the ischemic} brain

Interferon- $\gamma$ (IFN- $\gamma$ ) is one of the main cytokines produced by NK cells. Compared with sham-operated rats, IFN- $\gamma$ production increased more than 2-fold in the ischemic cortex of MCAO rats on Day 3 (17.9 \pm 4.7 v.s. $42.4 \pm 4.1 \mathrm{pg} / \mathrm{mg}, P<0.01$, Fig. $5 \mathrm{~A})$. However, the increased IFN- $\gamma$ production was markedly suppressed to $23.2 \pm 5.7 \mathrm{pg} / \mathrm{mg}$ by BHD treatment $(P<0.05)$.

CXCL10 is one of the major chemokines, which can chemotactically recruit NK cells to the ischemic brain [7]. We evaluated the effects of BHD on brain ischemia-induced CXCL10 upregulation in the ischemic cortex on Day 3 after MCAO. CXCL10 mRNA level increased nearly 4-fold after MCAO compared with sham-operated rats $(P<0.001)$, and BHD robustly decreased it to a level similar to that in sham controls $(P<0.01$, Fig. 5B). Abundant CXCL10 protein was found in the ipsilateral cortex, as revealed by immunofluorescence staining (Fig. 5D). On the contrary, CXCL10 was barely observed in the brain regions of sham control rats. As shown in the quantification data, brain ischemia induced a 12-fold upregulation in the protein levels of CXCL10 in the ipsilateral cortex compared with those in sham controls $(P<0.001$, Fig. 5C). Consistent with the effects on mRNA level, BHD also robustly suppressed the induction of CXCL10 protein in the cortex after brain ischemia (3-fold v.s. 12-fold, $P<0.001$, Fig. 5C). Furthermore, CXCL10 was found to be well colocalized with endothelial

Fig. 5. BHD suppressed IFN- $\gamma$ production and reduced CXCL10 levels in the ischemic cortex on Day 3 after MCAO. (A) IFN- $\gamma$ production was
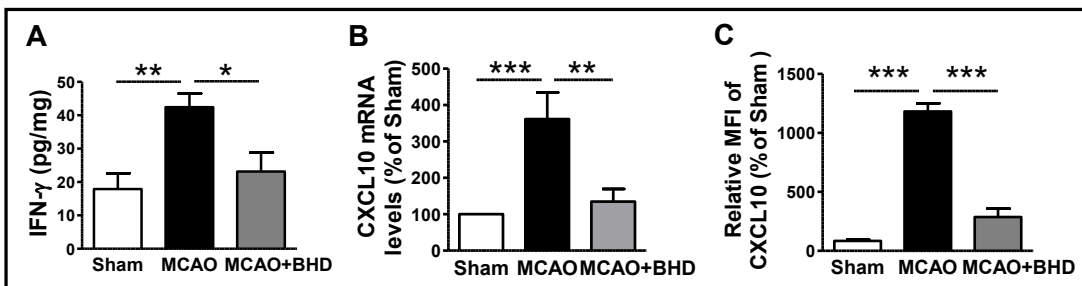

significantly increased in the ischemic cortex, whereas BHD treatment markedly reduced it. (B) BHD robustly downregulated MCAOinduced upregulation

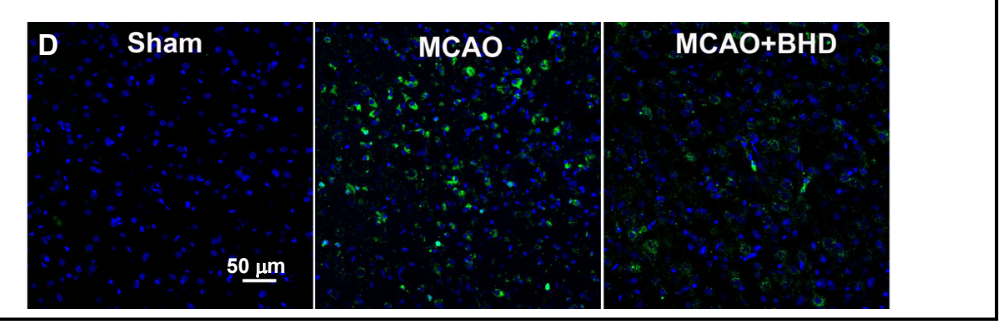
of CXCL10 mRNA

levels. (C and D) Abundant CXCL10 protein levels were observed in the ischemic cortex compared with the sham controls. BHD markedly reduced CXCL10 protein expression in the ipsilateral cortex. ${ }^{*} \mathrm{P}<0.05,{ }^{* *} \mathrm{P}<0.01$, ${ }^{* * *} \mathrm{P}<0.001 ; \mathrm{n}=6$. 


\section{Cellular Physiology Cell Physiol Biochem 2018;50:1286-1300 \begin{tabular}{l|l|l} 
DOl: 10.1159/000494587 & $\begin{array}{l}\text { O 2018 The Author(s). Published by S. Karger AG, Basel } \\
\text { www.karger.com/cpb }\end{array}$
\end{tabular} Dou et al.: BHD Inhibits NK Cell Infiltration into Ischemic Brain}

cells (Fig. 6A), partially with microglial cells (Fig. 6B) and neutrophils (Fig. 6C), but not astrocytes or neurons (data not shown), as double-stained with RECA-1 for endothelial cells, Iba1 for microglial cells, GFAP for astrocytes, NeuN for neurons, or MPO for neutrophils.

BHD decreased the expression of CXCR3 on brain-infiltrated NK cells, but not on NK cells in the spleen and blood

CXCL10 exerts effects by binding to its receptor CXCR3. Therefore, we examined the effects of BHD on CXCR3 expression on brain-infiltrated NK cells, as well as NK cells in the spleen and blood on Day 3 after MCAO. CXCR3 expression on NK cells was identified as $\mathrm{CD} 161^{+}{ }^{+} \mathrm{CD} 3{ }^{-} \mathrm{CXCR} 3^{+}$cells using flow cytometry. CXCR3 expression was significantly increased on the surface of brain-infiltrated NK cells in MCAO rats compared with sham-operated rats $(P<0.01)$, and this increase was markedly suppressed by post-ischemic treatment with BHD $(P<0.05$, Fig. 7A). Consistent with the effects of BHD on peripheral NK cell levels, BHD did not affect CXCR3 expression on the NK cells in the spleen or the blood (Fig. 7B and C).

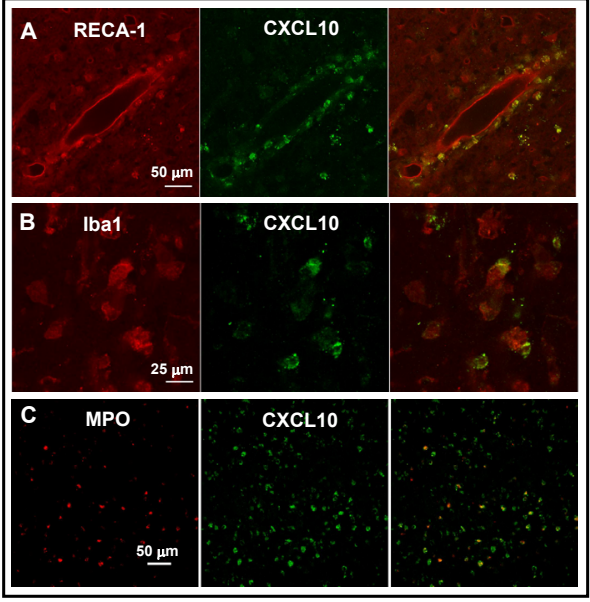

Fig. 6. CXCL10 was mainly produced by endothelial cells, and partially by microglial cells and neutrophils in the ischemic cortex on Day 3 after MCAO. (A) CXCL10 was well colocalized with endothelial cells as stained with RECA-1. (B) CXCL10 was partially colocalized with microglial cells as labeled with Iba1. (C) CXCL10 was partially colocalized with neutrophils as labeled with MPO.

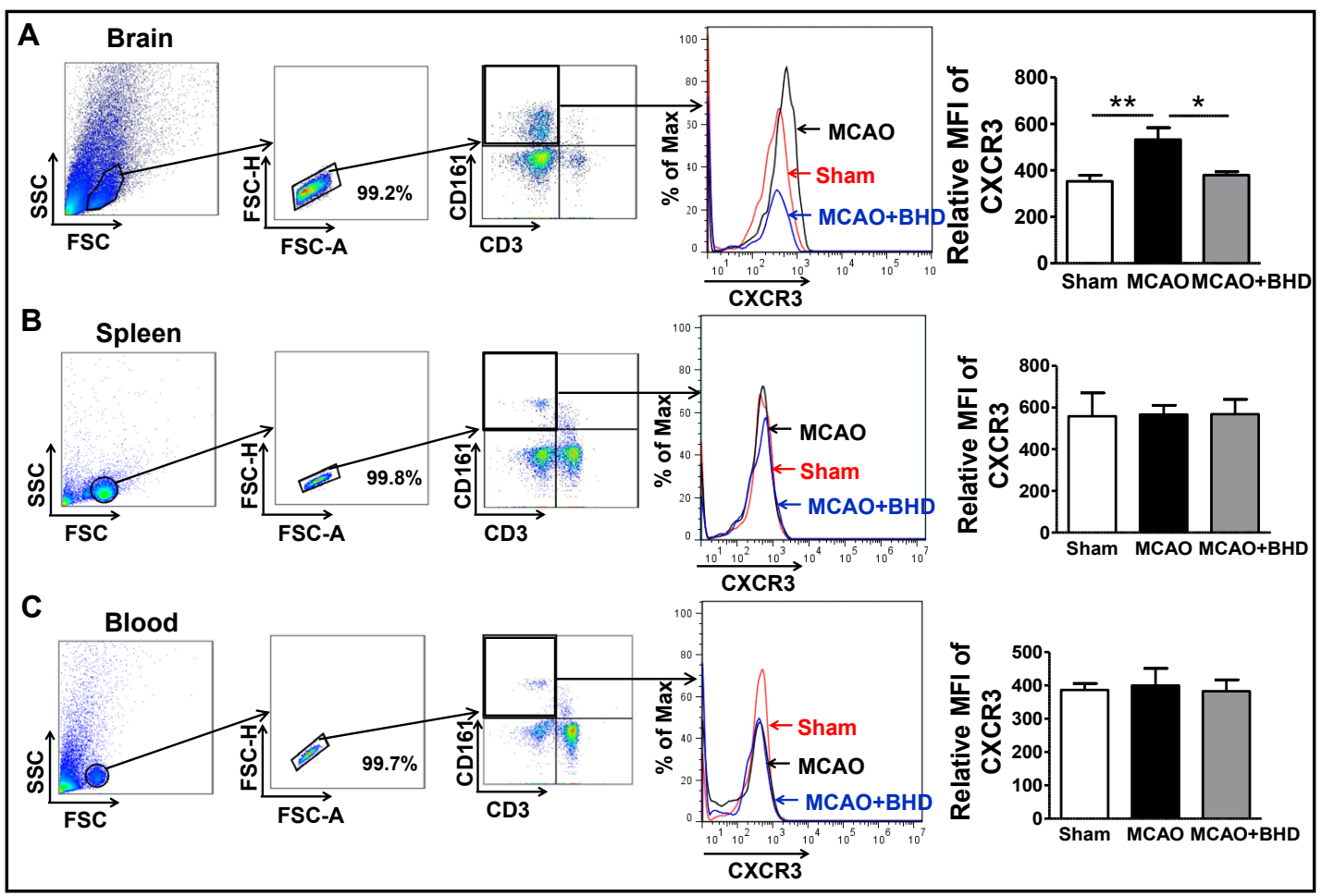

Fig. 7. BHD reduced CXCR3 expression on brain-infiltrated NK cells, but not on NK cells in the periphery on Day 3 after MCAO. (A) MCAO induced a significant increase of CXCR3 expression on NK cells that infiltrated into the ischemic cortex, and this increase was markedly inhibited by BHD treatment. Neither brain ischemia nor post-ischemic BHD treatment affected the CXCR3 expression on NK cells in the spleen (B) or blood (C). ${ }^{*} \mathrm{P}<0.05,{ }^{* *} \mathrm{P}<0.01 ; \mathrm{n}=6$. 


\section{Cellular Physiology Cell Physiol Biochem 2018;50:1286-1300 and Biochemistry \begin{tabular}{l|l} 
DOI: 10.1159/000494587 & (c) 2018 The Author(s). Published by S. Karger AG, Basel \\
www.karger.com/cpb
\end{tabular}

Fig. 8. BHD inhibited $\mathrm{NF}-\kappa \mathrm{B}$ activation in the ischemic cortex on Day 3 after MCAO. (A and B) MCAO induced the nuclear translocation of NF- $\mathrm{NB}$ p65 and phospho-p65 in the ischemic cortex, and both were significantly inhibited by BHD treatment, as shown in Western blots.

(C) MCAO induced p65 production and nuclear accumulation in the ischemic cortex, as assessed by immunofluorescence

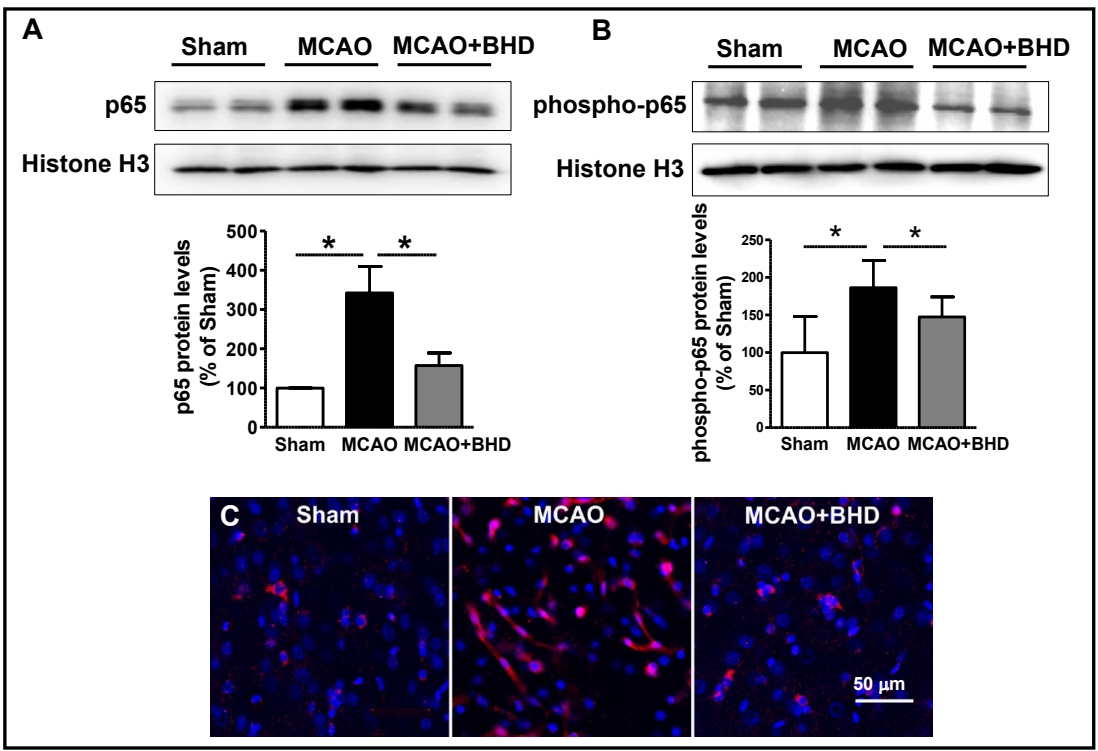
staining, and both were robustly suppressed by BHD treatment. ${ }^{*} \mathrm{P}<0.05 ; \mathrm{n}=6$.

$B H D$ inhibited nuclear factor $-\kappa B(N F-\kappa B)$ activation in the ischemic brain

As a transcription factor, NF- $\kappa B$ plays an important role in post-ischemic inflammation and regulates the transcription of abundant cytokines, chemokines and immune receptors. As expected, brain ischemia induced the nuclear translocation of the p65 subunit of NF$\kappa \mathrm{B}(P<0.05$, Fig. 8A) and phospho-p65 $(P<0.05$, Fig. 8B) on Day 3 after MCAO, and p65 and phospho-p65 nuclear translocation was markedly inhibited by BHD, as assessed by Western blotting $(P<0.05)$. We further stained p65 with DAPI counterstaining to confirm the inhibitory effects of BHD on MCAO-induced p65 nuclear translocation. As shown in Fig. 8C, MCAO induced p65 production and nuclear accumulation in the ischemic cortex, and both were robustly suppressed by BHD treatment.

\section{Discussion}

This study demonstrated that BHD, a well-known traditional Chinese herbal prescription, possessed the ability to prevent NK cells from infiltrating into the brain following cerebral ischemia. CXCL10 is the primary chemokine that attracts NK cells to the ischemic brain through its receptor CXCR3. BHD inhibited brain ischemia-induced upregulation of CXCL10, which was mainly produced by microvascular endothelial cells and partially by microglial cells and neutrophils in respond to IFN- $\gamma$ in the ischemic hemisphere. Concurrently, MCAOinduced upregulation of CXCR3 on the surface of brain-infiltrated NK cells was also suppressed by BHD. Therefore, the ability of BHD to prevent brain infiltration of NK cells following brain ischemia may involve inhibition of the CXCL10-induced chemotaxis of CXCR3-expressing NK cells. Suppression of NK cell brain infiltration may contribute to the beneficial effects of BHD to attenuate BBB disruption, reduce brain infarction, and eventually ameliorate functional deficits.

BHD is a well-known traditional Chinese herbal prescription, and is commonly used in the sequelae stage treatment of ischemic stroke patients in China. A meta-analysis of 19 randomized controlled trials has suggested that BHD is generally safe and can improve neurological deficits in treatment of acute ischemic stroke [9]. BHD has also been shown to have neuroprotective effects in animal models of focal cerebral ischemia [10]. In our study, we evaluated the neuroprotective effects of 7 and $14 \mathrm{~g} / \mathrm{kg} /$ day BHD, and the latter dosage 


\section{Cellular Physiology Cell Physiol Biochem 2018;50:1286-1300 \begin{tabular}{l|l|l} 
and Biochemistry & DOl: 10.1159/000494587 & $\begin{array}{l}\text { O } 2018 \text { The Author(s). Published by S. Karger AG, Basel } \\
\text { www.karger.com/cpb }\end{array}$
\end{tabular} \\ Dou et al.: BHD Inhibits NK Cell Infiltration into Ischemic Brain}

was translated from human according to the body surface area normalization method [21]. Compared with $7 \mathrm{~g} / \mathrm{kg} /$ day, BHD at $14 \mathrm{~g} / \mathrm{kg} /$ day produced significant better neuroprotective effects, and this result is consistent with a previous study [22].

As quality control, we identified eight representative bioactive compounds in the water decoction of BHD according to the Chinese Pharmacopoeia and previous reports $[18,19]$. Huangqi is the monarch drug of BHD. To develop a sensitive and accurate LC-MS/MS method for the determination of astragaloside IV, a representative bioactive ingredient of Huangqi, a triple quadruple mass spectrometer equipped with ESI was used to analyze the samples. It was found that the negative mode could offer higher sensitivities than the positive mode. By negative ESI, the $[\mathrm{M}+\mathrm{HCOO}]-$ and $[\mathrm{M}-\mathrm{H}]$ - ions were chosen as the precursor and product ions to obtain the highest intensity for MRM analysis. In optimizing the LC system for the accurate detection of astragaloside IV, the isocratic systems achieved shape peak and good separation with its isomer.

Clinical and experimental studies have highlighted that inflammatory and immune responses in the brain may determine the outcomes of stroke. Therefore, immune interventions hold great promise for the treatment of stroke [23]. Brain ischemia triggers a strong inflammatory response, which recruits lymphocytes to the ischemic brain [1, 2]. NK cells are among the first lymphocytes that invade the brain parenchyma within hours after stroke onset, followed by T and B cells [24]. Kinetics study has revealed that infiltration of NK cells starts within hours, peaks at 3 days, and lasts at least 30 days after ischemia in the mouse brain [7]. The peak of NK cell infiltration is also observed in 2 to 5 days post-mortem ischemic human brains [7]. The present study found that one third of brain-infiltrated lymphocytes were NK cells on Day 3 after MCAO in rats, and this echoes the findings in ischemic mouse and human brains. Strikingly, BHD robustly inhibited NK cell infiltration to the ischemic brain. It has been shown that NK cells accelerate BBB disruption, catalyze neuronal death, and exacerbate brain infarction following brain ischemia [6, 7]. In addition, depletion of NK cells in mice robustly diminishes the brain infarction [7]. These brain-infiltrated NK cells have upregulated activating receptor NKG2D, and can directly kill neurons that have lost NK cell tolerance through loss of MHC Ib [6]. They are the major sources of IFN- $\gamma$, which can boost local inflammation, promote glutamate release, and induce hyperactivity and excitotoxicity in neurons [6]. NK cells also accelerate BBB disruption after brain ischemia via CXCL10-induced chemotaxis [7]. Therefore, the ability of preventing NK cell brain penetration may contribute to BHD's beneficial effects on BBB disruption, brain infarction and functional deficits in ischemic rats.

CXCL10 is a chemokine highly inducible by IFN- $\gamma$, and is a chemoattractant for NK cells in the brain [25]. Abundant evidence has indicated the increase of CXCL10 in rodent and human brains after ischemia [7, 26, 27]. Depletion of CXCL10 has been shown to abolish the brain infiltration of NK cells after ischemia, suggesting that CXCL10 attracts NK cells infiltrating into the ischemic brain [7]. In agreement with these findings, our current study showed that brain ischemia upregulated both the mRNA and protein levels of CXCL10 in rat brains, and these upregulations were robustly reduced by BHD. CXCL10 can be produced by several types of brain cells [25]. In our experimental setting, CXCL10 was found to be primarily produced by ischemic endothelial cells, and partially by microglial cells and neutrophils. Therefore, our findings suggested that BHD may suppress CXCL10 derived from multiple cell types in the ischemic brain, including local brain cells (endothelial cells), inflammatory cells (microglial cells) and infiltrated immune cells (neutrophils), and these effects may eventually inhibit NK cell brain infiltration.

CXCR3, the receptor of CXCL10, highly expresses on NK cells, and its expression is dominantly driven by IFN- $\gamma$ [28]. It has been reported that CXCR3 expression and CXCL10 binding are increased in rodent ischemic brains, and these findings suggest that CXCL10/ CXCR3 may be a potential therapeutic target in ischemic stroke $[7,29]$. In the present study, CXCR3 expression on brain-infiltrated NK cells was upregulated after MCAO, and this upregulation was markedly suppressed by BHD. Our findings further supported the notion 


\section{Cellular Physiology Cell Physiol Biochem 2018;50:1286-1300 \begin{tabular}{ll|l} 
DOI: 10.1159/000494587 & $\begin{array}{l}\text { O 2018 The Author(s). Published by S. Karger AG, Basel } \\
\text { www.karger.com/cpb }\end{array}$
\end{tabular} \\ Dou et al.: BHD Inhibits NK Cell Infiltration into Ischemic Brain}

that BHD may inhibit NK cell brain infiltration via suppression of CXCL10-CXCR3-mediated chemotaxis after brain ischemia.

NF- $\kappa \mathrm{B}$ activation plays a pivotal role in the induction of CXCL10 in response to IFN- $\gamma$ $[30,31]$. Concurrent with induction of IFN- $\gamma$, we also found p65 and phospho-p65 nuclear translocation in the ischemic brain on Day 3 after MCAO, indicating the activation of NF$\kappa \mathrm{B}$. BHD markedly inhibited IFN- $\gamma$ levels and the nuclear translocation of p65 and its phosphorylated form, suggesting that BHD may reduce brain ischemia-induced CXCL10 production via inhibiting IFN $-\gamma$ secretion and NF- $\kappa B$ activation. It has been shown that inhibition of NF- $\kappa B$ downregulates the transcription of CXCR3 [32]. In addition to CXCL10 and CXCR3, the transcription of MMP-2 and 9 also depends on NF- $\kappa B ~[33,34]$. In the acute stage of ischemic stroke, upregulation of MMP-2 and 9 has been linked to BBB disruption and leukocyte infiltration via degrading the basal components and tight junction proteins of BBB [20]. As aforementioned, we found that endothelial cell, the main component of BBB, was one of the major cell types that produce CXCL10 in the ischemic rat brain. Therefore, the BBB protection of BHD may involve the inhibition of NF- $\kappa B$ and its target genes, and thus contribute to the prevention of NK cell infiltration in the ischemic brain.

It is well noted that ischemic brain induces potent peripheral immunosuppression and incurs intercurrent infections, which are a major cause of morbidity and mortality in stroke patients $[1,23]$. Patients suffered from ischemic stroke exhibit marked reduced spleen size and circulating NK cell numbers during acute phase of stroke onset, and these phenomena are also observed in MCAO mice [35]. In line with these findings, the present study also observed a slight decrease in the percentage of NK cells of lymphocytes in both spleen and circulating blood. Brain ischemia activates catecholaminergic and hypothalamicpituitary-adrenal (HPA) axis, which leads to immunity suppression in the periphery [35]. It is noteworthy that BHD treatment did not affect the NK cell levels in either the spleen or blood following brain ischemia. The absent effects of BHD on peripheral NK cells after brain ischemia suggest that BHD may not affect the adrenergic and HPA axis pathways. Furthermore, neither MCAO nor BHD treatment affected CXCR3 expression on NK cells in the spleen or blood. The mechanism underlying different effects of BHD on brain-infiltrated and peripheral NK cells requires further investigation. Together, our results suggested that BHD may only suppress NK cells and their CXCR3 expression in the ischemic brain, instead of those in periphery. These findings may partially explain the clinical safety and efficacy of BHD for acute ischemic stroke.

To our knowledge, this study is the first to demonstrate that BHD prevents the postischemic brain infiltration of NK cells, and this may contribute to its effects in reducing brain infarction, attenuating BBB disruption, and improving functional outcomes. The inhibitory effect of BHD on NK cell brain infiltration may involve its ability of suppressing NF- $\kappa \mathrm{B}$ associated CXCL10 production in the ischemic brain cells and CXCR3 expression on braininfiltrated NK cells. It is also important to note that the effects of BHD on NK cells and their CXCR3 expression are restricted to the ischemic brain, suggesting that BHD may not affect post-ischemic peripheral immunosuppression of NK cells. Thus, our findings lead to a better understanding of the utility and safety of BHD against ischemic stroke in the clinical practice.

\section{Acknowledgements}

This study was supported by the National Natural Science Foundation of China (81503055 and 81873029) and Shanghai Youth Eastern Scholar (QD2015037). The authors thank Dr. De-Maw Chuang from the National Institute of Mental Health, National Institutes of Health for the comments. 


\section{Cellular Physiology Cell Physiol Biochem 2018;50:1286-1300 and Biochemistry Published \begin{tabular}{l|l} 
DOI: 10.1159/000494587 & $\begin{array}{l}\text { c } 2018 \text { The Author(s). Published by S. Karger AG, Basel } \\
\text { www.karger.com/cpb }\end{array}$
\end{tabular} \\ Dou et al.: BHD Inhibits NK Cell Infiltration into Ischemic Brain}

\section{Disclosure Statement}

The authors declare no competing interests.

\section{References}

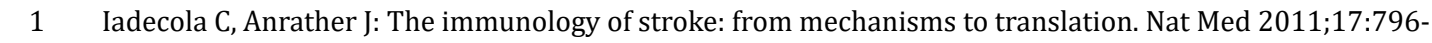
808.

2 Macrez R, Ali C, Toutirais O, Le Mauff B, Defer G, Dirnagl U, Vivien D: Stroke and the immune system: from pathophysiology to new therapeutic strategies. Lancet Neurol 2011;10:471-480.

-3 Cerwenka A, Lanier LL: Natural killer cell memory in infection, inflammation and cancer. Nat Rev Immunol 2016;16:112-123.

-4 Vivier E, Raulet DH, Moretta A, Caligiuri MA, Zitvogel L, Lanier LL, Yokoyama WM, Ugolini S: Innate or adaptive immunity? The example of natural killer cells. Science 2011;331:44-49.

5 Poli A, Kmiecik J, Domingues O, Hentges F, Blery M, Chekenya M, Boucraut J, Zimmer J: NK cells in central nervous system disorders. J Immunol 2013;190:5355-5362.

6 Gan Y, Liu Q, Wu W, Yin JX, Bai XF, Shen R, Wang Y, Chen J, La Cava A, Poursine-Laurent J, Yokoyama W, Shi FD: Ischemic neurons recruit natural killer cells that accelerate brain infarction. Proc Natl Acad Sci U S A 2014;111:2704-2709.

7 Zhang Y, Gao Z, Wang D, Zhang T, Sun B, Mu L, Wang J, Liu Y, Kong Q, Liu X, Zhang Y, Zhang H, He J, Li H, Wang G: Accumulation of natural killer cells in ischemic brain tissues and the chemotactic effect of IP-10. J Neuroinflammation 2014;11:79.

-8 Lehmann J, Hartig W, Seidel A, Fuldner C, Hobohm C, Grosche J, Krueger M, Michalski D: Inflammatory cell recruitment after experimental thromboembolic stroke in rats. Neuroscience 2014;279:139-154.

-9 Hao CZ, Wu F, Shen J, Lu L, Fu DL, Liao WJ, Zheng GQ: Clinical efficacy and safety of buyang huanwu decoction for acute ischemic stroke: a systematic review and meta-analysis of 19 randomized controlled trials. Evid Based Complement Alternat Med 2012;2012:630124.

10 Wei RL, Teng HJ, Yin B, Xu Y, Du Y, He FP, Chu KT, Luo BY, Zheng GQ: A systematic review and meta-analysis of buyang huanwu decoction in animal model of focal cerebral ischemia. Evid Based Complement Alternat Med 2013;2013:138484.

11 Chen HJ, Shen YC, Shiao YJ, Liou KT, Hsu WH, Hsieh PH, Lee CY, Chen YR, Lin YL: Multiplex brain proteomic analysis revealed the molecular therapeutic effects of Buyang Huanwu Decoction on cerebral ischemic stroke mice. PLoS One 2015;10:e0140823.

12 Wang HW, Liou KT, Wang YH, Lu CK, Lin YL, Lee IJ, Huang ST, Tsai YH, Cheng YC, Lin HJ, Shen YC: Deciphering the neuroprotective mechanisms of Bu-yang Huan-wu decoction by an integrative neurofunctional and genomic approach in ischemic stroke mice. J Ethnopharmacol 2011;138:22-33.

13 Shen YC, Lu CK, Liou KT, Hou YC, Lin YL, Wang YH, Sun HJ, Liao KH, Wang HW: Common and unique mechanisms of Chinese herbal remedies on ischemic stroke mice revealed by transcriptome analyses. J Ethnopharmacol 2015;173:370-382.

14 Tsai LK, Wang Z, Munasinghe J, Leng Y, Leeds P, Chuang DM: Mesenchymal stem cells primed with valproate and lithium robustly migrate to infarcted regions and facilitate recovery in a stroke model. Stroke 2011;42:2932-2939.

15 Wang Z, Leng Y, Tsai LK, Leeds P, Chuang DM: Valproic acid attenuates blood-brain barrier disruption in a rat model of transient focal cerebral ischemia: the roles of HDAC and MMP-9 inhibition. J Cereb Blood Flow Metab 2011;31:52-57.

16 Wang Z, Leng Y, Wang J, Liao HM, Bergman J, Leeds P, Kozikowski A, Chuang DM: Tubastatin A, an HDAC6 inhibitor, alleviates stroke-induced brain infarction and functional deficits: potential roles of alpha-tubulin acetylation and FGF-21 up-regulation. Sci Rep 2016;6:19626.

17 Wang Z, Tsai LK, Munasinghe J, Leng Y, Fessler EB, Chibane F, Leeds P, Chuang DM: Chronic valproate treatment enhances postischemic angiogenesis and promotes functional recovery in a rat model of ischemic stroke. Stroke 2012;43:2430-2436.

18 Huang H, Zhu H, Hu D, Zhang J, Han B: HPLC Fingerprint of Buyang Huanwu Decoction. Traditional Chinese Drug Research \& Clinical Pharmacology 2015;26:814-832. 


\section{Cellular Physiology Cell Physiol Biochem 2018;50:1286-1300

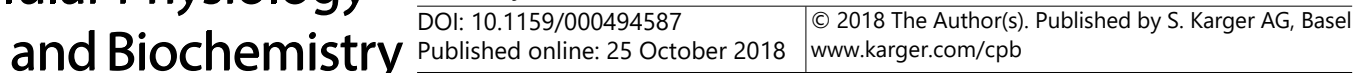

19 Zou L, Peng LX, Luo JY, HE FY, Zhao G: Fingerprint Analysis of the Chinese Traditional Medicine "Buyanghuanwu Decoction" by HPLC. Journal of Southwest University (Natural Science Edition) 2009;31:48-51.

20 Rosell A, Lo EH: Multiphasic roles for matrix metalloproteinases after stroke. Curr Opin Pharmacol 2008;8:82-89.

-21 Reagan-Shaw S, Nihal M, Ahmad N: Dose translation from animal to human studies revisited. FASEB J 2008;22:659-661.

22 Liu BY, Cai GX, Liu W, Chen XM: Effect of Buyang Huanwu Decoction on vascular endothelial growth factor and its receptor Flk1 in rats after focal cerebral ischemia. Chinese Traditional and Herbal Drugs 2007;38:394-397.

-23 Fu Y, Liu Q Anrather J, Shi FD: Immune interventions in stroke. Nat Rev Neurol 2015;11:524-535.

24 Gelderblom M, Leypoldt F, Steinbach K, Behrens D, Choe CU, Siler DA, Arumugam TV, Orthey E, Gerloff C, Tolosa E, Magnus T: Temporal and spatial dynamics of cerebral immune cell accumulation in stroke. Stroke 2009;40:1849-1857.

25 Muller M, Carter S, Hofer MJ, Campbell IL: Review: The chemokine receptor CXCR3 and its ligands CXCL9, CXCL10 and CXCL11 in neuroimmunity--a tale of conflict and conundrum. Neuropathol Appl Neurobiol 2010;36:368-387.

26 Li HL, Kostulas N, Huang YM, Xiao BG, van der Meide P, Kostulas V, Giedraitas V, Link H: IL-17 and IFNgamma mRNA expression is increased in the brain and systemically after permanent middle cerebral artery occlusion in the rat. J Neuroimmunol 2001;116:5-14.

27 Wang X, Ellison JA, Siren AL, Lysko PG, Yue TL, Barone FC, Shatzman A, Feuerstein GZ: Prolonged expression of interferon-inducible protein-10 in ischemic cortex after permanent occlusion of the middle cerebral artery in rat. J Neurochem 1998;71:1194-1204.

-28 Pak-Wittel MA, Yang L, Sojka DK, Rivenbark JG, Yokoyama WM: Interferon-gamma mediates chemokinedependent recruitment of natural killer cells during viral infection. Proc Natl Acad Sci U S A 2013;110:E5059.

29 Wang X, Li X, Schmidt DB, Foley JJ, Barone FC, Ames RS, Sarau HM: Identification and molecular characterization of rat CXCR3: receptor expression and interferon-inducible protein-10 binding are increased in focal stroke. Mol Pharmacol 2000;57:1190-1198.

30 Antonelli A, Ferrari SM, Fallahi P, Piaggi S, Paolicchi A, Franceschini SS, Salvi M, Ferrannini E: Cytokines (interferon-gamma and tumor necrosis factor-alpha)-induced nuclear factor-kappaB activation and chemokine (C-X-C motif) ligand 10 release in Graves disease and ophthalmopathy are modulated by pioglitazone. Metabolism 2011;60:277-283.

-31 Marx N, Mach F, Sauty A, Leung JH, Sarafi MN, Ransohoff RM, Libby P, Plutzky J, Luster AD: Peroxisome proliferator-activated receptor-gamma activators inhibit IFN-gamma-induced expression of the T cellactive CXC chemokines IP-10, Mig, and I-TAC in human endothelial cells. J Immunol 2000;164:6503-6508.

-32 Yang CH, Fang IM, Lin CP, Yang CM, Chen MS: Effects of the NF-kappaB inhibitor pyrrolidine dithiocarbamate on experimentally induced autoimmune anterior uveitis. Invest Ophthalmol Vis Sci 2005;46:1339-1347.

-33 Van den Steen PE, Dubois B, Nelissen I, Rudd PM, Dwek RA, Opdenakker G: Biochemistry and molecular biology of gelatinase B or matrix metalloproteinase-9 (MMP-9). Crit Rev Biochem Mol Biol 2002;37:375536.

34 Bilandzic M, Wang Y, Ahmed N, Luwor RB, Zhu HJ, Findlay JK, Stenvers KL: Betaglycan blocks metastatic behaviors in human granulosa cell tumors by suppressing NFkappaB-mediated induction of MMP2. Cancer Lett 2014;354:107-114.

-35 Liu Q, Jin WN, Liu Y, Shi K, Sun H, Zhang F, Zhang C, Gonzales RJ, Sheth KN, La Cava A, Shi FD: Brain Ischemia Suppresses Immunity in the Periphery and Brain via Different Neurogenic Innervations. Immunity 2017;46:474-487. 